\title{
Galactose, Glucose, and Lactate Concentrations in the Portal Venous and Arterial Circulations of Newborn Lambs after Nursing ${ }^{1}$
}

\author{
JOSEPH W. KAEMPF, HAI-QI LI, JESSIE R. GROOTHUIS, FREDERICK C. BATTAGLIA, \\ GARY O. ZERBE, AND JOHN W. SPARKS \\ Division of Perinatal Medicine, Department of Pediatrics, University of Colorado School of Medicine, Denver, \\ Colorado 80262
}

\begin{abstract}
We have used the newborn lamb prepared with chronic indwelling catheters to study carbohydrate metabolism in the unstressed, postprandial state. Lambs were fasted $5 \mathrm{~h}$ and then allowed to nurse ad libitum from their mothers for $20 \mathrm{~min}$. Serial determinations of whole blood galactose, glucose, and lactate concentration were then made from the portal venous and arterial circulations. Portal venous galactose concentration increased significantly after milk ingestion, but arterial galactose concentration did not increase from baseline unless the portal venous galactose concentration exceeded $10-12 \mathrm{mg} / \mathrm{dl}$ suggesting a threshold effect for hepatic galactose clearance. Glucose concentration increased significantly in both circulations with portal venous galactose concentration > arterial galactose concentration in all cases. Galactose and glucose were absorbed from the intestine at approximately equal rates. Lactate was not absorbed into the portal venous circulation to any great extent after lactose ingestion. (Pediatr Res 23: 598-602, 1988)
\end{abstract}

Abbreviations

$\mathrm{Gal}_{\boldsymbol{A}}$, arterial galactose concentration

$\mathrm{Gal}_{\mathrm{Pv}}$, portal venous galactose concentration

$\mathrm{Glu}_{\mathrm{A}}$, arterial glucose concentration

Glu $_{P V}$, portal venous glucose concentration

PV-A, portal venous concentration minus arterial concentration

Lactose is a carbohydrate with several unique and intriguing characteristics. It is the sole dietary carbohydrate of nearly all newborn mammals, and except in humans, is consumed exclusively in the neonatal period. Galactose, one of its component monosaccharides, is not an important substrate in the fetus (1) but can represent up to $20 \%$ of the caloric intake of the neonate (2). Despite the importance of lactose and galactose in the newborn diet, their neonatal metabolism is incompletely understood.

Recently, we have described the postprandial change in galactose and glucose concentrations in the peripheral blood of newborn infants seen after a single milk feeding (3). There was a

Received September 2, 1987; accepted February 2, 1988.

Correspondence and reprint requests Frederick C. Battaglia, M.D., Division of Perinatal Medicine, Box B-199, University of Colorado Health Sciences Center 4200 East Ninth Avenue, Denver, CO 80262.

Supported by NIH Program Grant HD-00781. J.W.K. was supported by Training Grant HD-07186.

${ }^{1}$ Presented in part at the annual meeting of The Society for Pediatric Research, Anaheim, CA, May 1987 striking difference in the metabolism of the two carbohydrates. To investigate this phenomenon in more depth, our study was carried out in newborn lambs with chronic indwelling catheters placed in the portal venous and arterial circulations. Thus, lactose metabolism could be studied in an unstressed, newborn mammal immediately after a milk feeding.

\section{METHODS}

All lambs were of mixed Western breed, delivered spontaneously at term, and were in good health. They nursed solely from their mothers. Within the first 10 days of life the lambs were given general anesthesia with pentobarbital $(30 \mathrm{mg} / \mathrm{kg})$ and local lidocaine. One polyvinyl catheter $(0.054$ in OD, 0.034 in ID) was placed in the portal vein via an umbilical vein cutdown. A second catheter was placed in the femoral artery. The catheters were tunneled subcutaneously, exteriorized, and kept in a small side pouch for access. Penicillin (300,000 U) and streptomycin $(0.5 \mathrm{~g})$ were given intramuscularly on the day of surgery only. Care was taken to wash the surgical area free of betadine after surgery to facilitate acceptance by the lamb's mother. All lambs were allowed to recover with their mothers for a minimum of 48 h. No lamb lost weight and all were observed to be vigorous, nursing normally, and gaining weight at the time of the first study. Catheters were flushed every other day with heparin 100 $\mathrm{U} / \mathrm{ml}$. Catheter tip placement was confirmed at autopsy.

On the day of study the lambs were separated from their mothers and fasted for $5 \mathrm{~h}$ to ensure that the stomach and small intestine were empty of milk. At time 0 the lambs were weighed and baseline blood samples were drawn from the portal vein and femoral artery. The lambs were then allowed to nurse ad libitum from their mothers for $20 \mathrm{~min}$ and were weighed again to determine milk intake. There were no urine or stool losses during this 20 -min period. At times $30,40,60,80,100,120,140,160$, 190 , and $220 \mathrm{~min}$ after beginning nursing, samples were drawn from the portal vein and femoral artery catheters while the lambs rested quietly. Twenty-five studies were done on 11 lambs.

Chemical analyses. Concentrations of D-galactose, D-glucose, and L-lactate were measured on each whole blood sample. DGalactose was determined by the galactose oxidase method described by Hjelm and deVerdier (4). D-Glucose and L-lactate concentrations were determined using analyzers equipped with glucose oxidase and lactate oxidase membranes (Yellow Springs Analyzer, models 23 and 21, Yellow Springs, $\mathrm{OH}$ ).

Statistical analysis. The principal statistical tool used was analysis of variance as discussed by Freund and Littell (5) and Scheffe (6). The SAS statistical package (7) and, particularly, SAS PROC GLM were used to execute the analyses of variance.

First, we used repeated measures analysis of variance $(5,7)$ to analyze the data for each carbohydrate. Arterial values, venous 
values, and the PV-A differences were treated as dependent variables in analyses of variance including times, lambs, and experiments as factors. Lambs, experiments (treated as replicates within lambs), and their interactions with time were considered sources of random variation. Times were treated as repeated measurements during an experiment. This model was analyzed for the "nonspill" and "spill" data separately (see "Results" for definition of nonspill and spill) for simplicity and in order to use the maximal number of studies for both describing the time course of carbohydrate response and for comparing arterial with venous carbohydrate response curves. To facilitate description of the shape of the carbohydrate response curves regression techniques were used to partition the between times sums of square into components attributable to linear, quadratic, and cubic trends.

For the 20 nonspill studies on 10 lambs, separate SD reflecting the variability between lambs and the variability between experiments were estimated by maximum likelihood via SAS PROC VARCOMP (7). These variance components are reported in Table 1 . The variability between experiments was greater than the variability between lambs. Five studies on four lambs did not provide sufficient data for similar variance component estimation for the spill studies. Total variability tended to be greater for the spill studies than for the nonspill studies.

To compare carbohydrate response curves of nonspill and spill studies, spill status was added as a factor in the repeated measures analyses of variance. Six nonspill studies on three lambs with both spill and nonspill studies were deleted from the analysis to avoid partial cross-classification of lambs and spill status. Mean areas under the curves were estimated by a trapezoidal method and compared within this analysis of variance framework. The estimated areas under the curves are reported in Table 2.

Simpler nested analyses of variance were used to compare nonspill studies and spill studies with respect to variables that were not time dependent such as postnatal age, weight, fast-time, and milk intake. These analyses also accounted for both variability between lambs and variability between experiments. The relationship between arterial and portal venous galactose concentrations were examined by simple linear regressions.

\section{RESULTS}

Calactose. Figure 1 presents the relationship between the $\mathrm{Gal}_{\mathrm{A}}$ and $\mathrm{Gal}_{\mathrm{PV}}$ after milk feeding. At $\mathrm{Gal}_{\mathrm{PV}}$ less than $10 \mathrm{mg} / \mathrm{dl}$ there was no significant increase in the $\mathrm{Gal}_{\mathrm{A}}$ above baseline. When the

Table 1. Comparison of variance of carbohydrate concentration between 10 lambs and between 20 nonspill experiments in these same lambs by carbohydrate and by vessel

\begin{tabular}{|c|c|c|c|}
\hline & & Between lamb $\dagger$ & $\begin{array}{c}\text { Between } \\
\text { experimentsł }\end{array}$ \\
\hline Carbohydrate & Vessel* & $\sum(\mathrm{mg} / \mathrm{dl}) \dagger$ & $\sum(\mathrm{mg} / \mathrm{dl}) \dagger$ \\
\hline \multirow[t]{3}{*}{ Galactose } & FA & $0.0 \quad(0 \%)$ & $0.6(100 \%)$ \\
\hline & PV & $1.4(17 \%)$ & $7.0(83 \%)$ \\
\hline & FA-PV & $1.2(19 \%)$ & $5.3(81 \%)$ \\
\hline \multirow[t]{3}{*}{ Glucose } & FA & $48.6(38 \%)$ & $79.5 \quad(62 \%)$ \\
\hline & PV & $52.6(35 \%)$ & $99.8(65 \%)$ \\
\hline & FA-PV & $2.1(22 \%)$ & $7.4(78 \%)$ \\
\hline \multirow[t]{3}{*}{ Lactate } & FA & $1.9(21 \%)$ & $7.2(79 \%)$ \\
\hline & PV & $1.7(18 \%)$ & $7.6(82 \%)$ \\
\hline & FA-PV & $0.0 \quad(0 \%)$ & $0.8(100 \%)$ \\
\hline
\end{tabular}

* FA, femoral artery; PV, portal vein; FA-PV, arteriovenous difference.

$\dagger$ Computed as the sum of variances for additive and nonadditive (interactive with time) lamb effects.

$\$$ Computed as the sum of variances for additive and nonadditive experiment effects.
Table 2. Mean area under carbohydrate response curves after nursing*

\begin{tabular}{ccc}
$\begin{array}{c}\text { Femoral } \\
\text { artery }\end{array}$ & $\begin{array}{c}\text { Portal } \\
\text { vein }\end{array}$ & $\begin{array}{c}p \text { for } \\
\text { FA-PV } \dagger \text { difference }\end{array}$ \\
\hline
\end{tabular}

Nonspill study areas

$\begin{array}{lrrr}\text { Galactose } & 220 & 993 & 0.0001 \\ \text { Glucose } & 24,888 & 25,811 & 0.0001 \\ \text { Lactate } & 2,212 & 2,394 & 0.0001\end{array}$

Spill study areas

$\begin{array}{lrrr}\text { Galactose } & 1,180 & 2,554 & 0.0001 \\ \text { Glucose } & 27,430 & 28,571 & 0.0001 \\ \text { Lactate } & 2,997 & 3,136 & 0.0001\end{array}$

$p$ for area differences between nonspill and spill

Carbohydrate curves

$\begin{array}{llll}\text { Galactose } & 0.002 & 0.004 & 0.002 \\ \text { Glucose } & 0.052 & 0.048 & 0.177 \\ \text { Lactate } & 0.094 & 0.104 & 0.106\end{array}$

* See Figures $2 A$ and $B, 3 A$ and $B, 6 A$ and $B$.

$\dagger$ Arteriovenous difference.

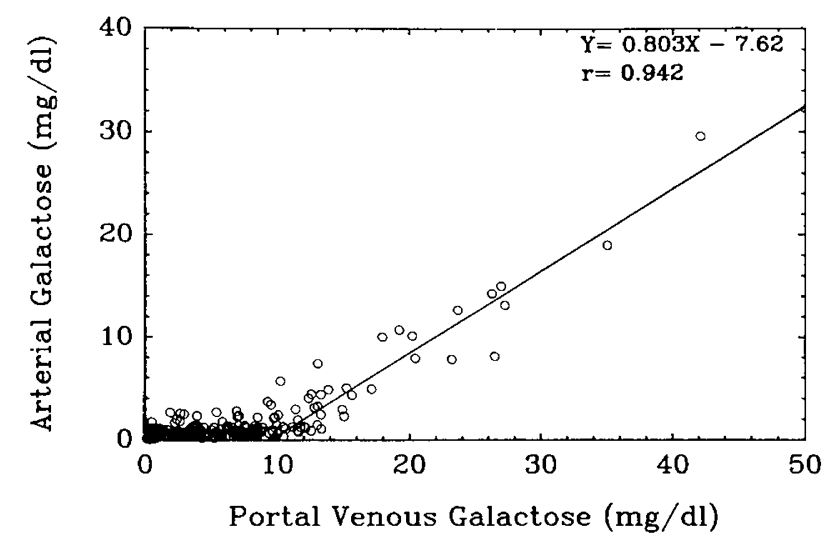

Fig. 1. $\mathrm{Gal}_{\mathrm{A}}$ versus $\mathrm{Gal}_{\mathrm{Pv}}$ after milk feeding in lambs. The paired $\mathrm{Gal}_{\mathrm{A}}$ and $\mathrm{Gal}_{\mathrm{PV}}$ values after nursing for all time points in all studies are shown.

$\mathrm{Gal}_{\mathrm{PV}}$ exceeded $12 \mathrm{mg} / \mathrm{dl}$, the $\mathrm{Gal}_{\mathrm{A}}$ increased significantly above baseline. This suggests a hepatic threshold for $\mathrm{Gal}_{\mathrm{PV}}$ of approximately $10-12 \mathrm{mg} / \mathrm{dl}$.

It was noted retrospectively that the only studies in which there was a significant increase in the $\mathrm{Gal}_{\mathrm{A}}$ were those in which the $\mathrm{Gal}_{\mathrm{pv}}$ exceeded $10-12 \mathrm{mg} / \mathrm{dl}$ at three or more time points after nursing. In $80 \%$ of the studies (20 studies in 10 lambs) the $\mathrm{Gal}_{\mathrm{Pv}}$ did not exceed $10-12 \mathrm{mg} / \mathrm{dl}$ after nursing, and for convenience, we have called these nonspill studies because of the lack of increase in $\mathrm{Gal}_{\mathrm{A}}$ ( $p>0.05$ using simple linear regression) as $\mathrm{Gal}_{\mathrm{PV}}$ rises. The $\mathrm{Gal}_{\mathrm{A}}$ and $\mathrm{Gal}_{\mathrm{PV}}$ versus time for these nonspill studies are shown graphically in Figure $2 A$. In these studies the $\mathrm{Gal}_{\mathrm{PV}}$ curve is strongly quadratic $(p<0.01)$, peaking at $80 \mathrm{~min}$. The $\mathrm{Gal}_{\mathrm{A}}$ curve appears flat, but actually has a slightly negative trend $(p<0.01)$.

In $20 \%$ of the studies (five studies in four lambs) the $\mathrm{Gal}_{\mathrm{PV}} \mathrm{did}$ exceed $10-12 \mathrm{mg} / \mathrm{dl}$ at three or more time points after nursing. We have called these spill studies because of the increase in $\mathrm{Gal}_{\mathrm{A}}$ ( $p<0.01$ using simple linear regression) as $\mathrm{Gal}_{\mathrm{PV}}$ exceeds $10-12$ $\mathrm{mg} / \mathrm{dl}$. These $\mathrm{Gal}_{\mathrm{A}}$ and $\mathrm{Gal}_{\mathrm{PV}}$ values are presented graphically in Figure $2 B$. The time course for both the $\mathrm{Gal}_{\mathrm{A}}$ and $\mathrm{Gal}_{\mathrm{PV}}$ curves in Figure $2 B$ are largely quadratic $(p<0.01)$. 

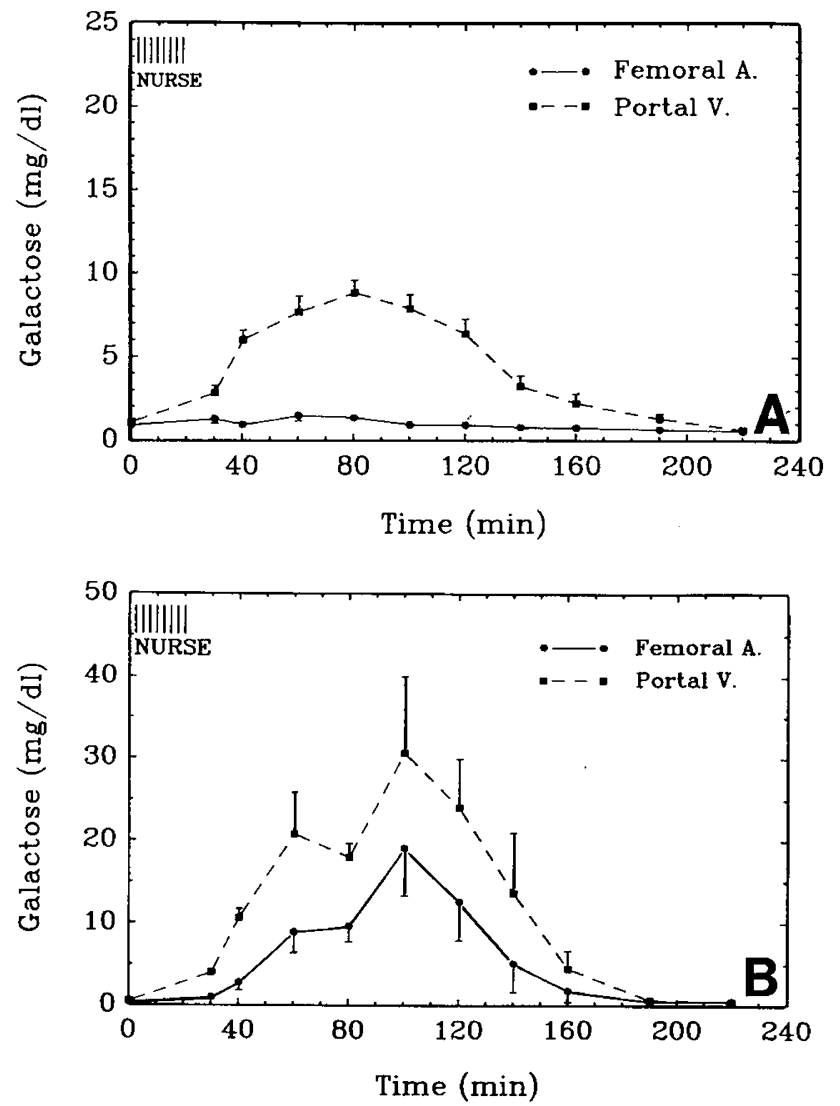

Fig. 2. $A$, arterial and portal venous galactose concentrations versus time after nursing for the nonspill studies (mean and SEM). $B$, arterial and portal venous galactose concentrations versus time after nursing for the spill studies (mean and SEM).

Glucose. The Glu $\mathrm{A}_{\mathrm{A}}$ and Glu $\mathrm{Pv}$ circulations after nursing for the nonspill and spill studies are presented in Figures $3 A$ and $B$, respectively. The changes in glucose concentration over time are highly significant $(p<0.01)$. Both the $\mathrm{Glu}_{\mathrm{A}}$ and Glu $\mathrm{PV}_{\mathrm{PV}}$ increased after feeding with $\mathrm{Glu}_{\mathrm{PV}}>\mathrm{Glu}_{\mathrm{A}}$ in all cases $(p<0.01)$. The Glu and $\mathrm{Glu}_{\mathrm{PV}}$ values were significantly greater in the spill studies than their respective counterparts in the nonspill studies $(p<$ 0.05 for both carbohydrates).

Lactate. The postprandial lactate concentrations in the arterial and portal venous circulations are presented in Figure 4. The data were combined because there was no significant difference between the nonspill and spill studies $(p>0.15)$. There were small but significant increases of similar magnitude in both the arterial and portal venous lactate concentrations after nursing ( $p$ $<0.01$ )

Comparisons of nonspill versus spill studies. There was no correlation between time from catheter placement and whether a lamb had a nonspill or spill study on a particular day. Nonspill and spill studies were compared for postnatal age, weight, fasttime, and milk intake for each lamb on each study day. Means \pm SE for these factors are shown in Figure 5. Age, weight, and fast-time did not differ between the groups $(p>0.25)$, but the milk intake was significantly greater in the spill studies, $58 \pm 4$ $\mathrm{g} / \mathrm{kg}(\sim 2.5 \mathrm{~g}$ lactose $/ \mathrm{kg})$ versus $41 \pm 3 \mathrm{~g} / \mathrm{kg}(\sim 1.8 \mathrm{~g}$ lactose $/ \mathrm{kg})$ in the nonspill studies $(p<0.05)$.

The study design permitted the lambs to nurse ad libitum for a 20-min period; hence, milk intake was not controlled. Thus, the variability of milk intake reflects biologic variability in suckling patterns. Seven lambs had one or more nonspill studies only, one had two spill studies only, and three lambs had both types of studies on separate study days. The great proportion of the total variance in carbohydrate concentration was due to interexperiment variability and not to interlamb variability (Table 1).
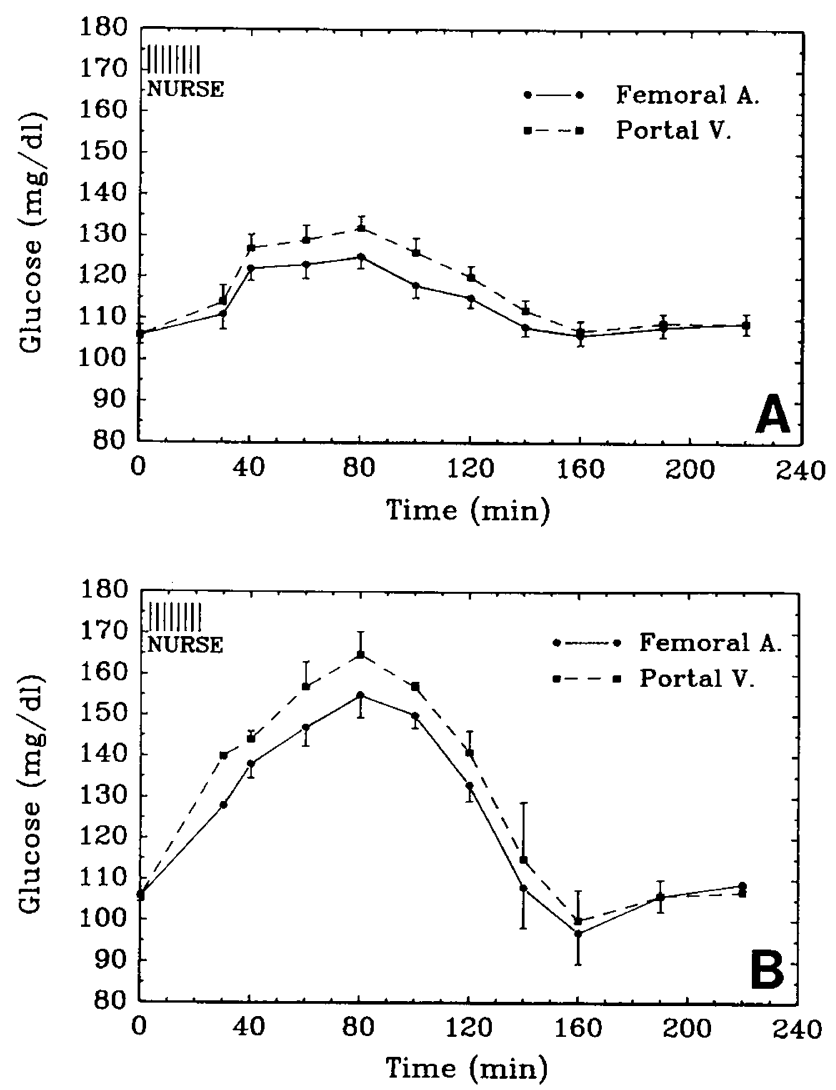

Fig. 3. $A$, arterial and portal venous glucose concentrations versus time after nursing for the nonspill studies (mean and SEM). $B$, arterial and portal venous glucose concentrations versus time after nursing for the spill studies (mean and SEM).

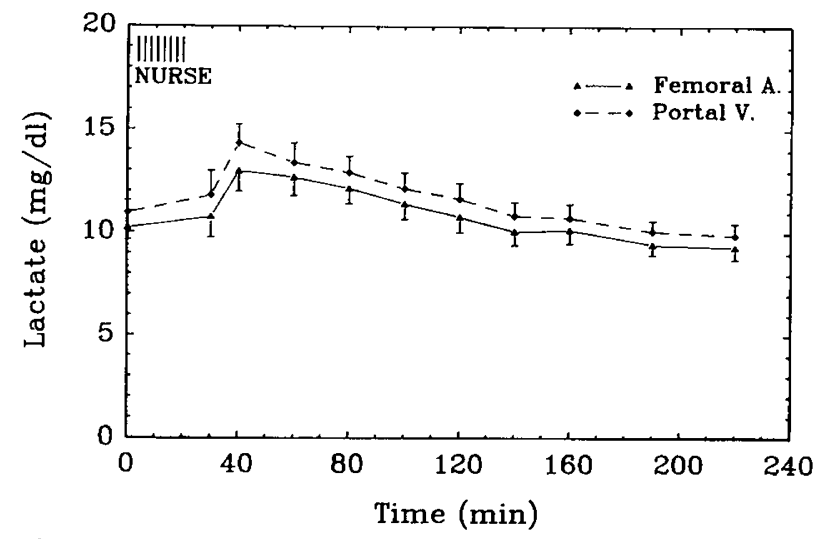

Fig. 4. Arterial and portal venous lactate concentrations yersus time after nursing for both nonspill and spill studies combined (mean and SEM).

Figures $6 A$ and $B$ plot the PV-A versus time for the nonspill and spill studies, respectively. In the nonspill studies (Fig. 6A) the PV-A curves for galactose and glucose are quite similar, i.e. $\left(\mathrm{Gal}_{\mathrm{PV}}-\mathrm{Gal}_{\mathrm{A}}\right) /\left(\mathrm{Glu}_{\mathrm{PV}}-\mathrm{Glu}_{\mathrm{A}}\right), \sim 1.0$, suggesting that galactose and glucose are absorbed from the intestine at approximately equal rates after lactose ingestion. In the spill studies (Fig. 6B) there was much greater variance in the $\mathrm{Gal}_{\mathrm{A}}$ values because of the larger $\mathrm{Gal}_{\mathrm{pv}}$ values which frequently exceeded $10-12 \mathrm{mg} / \mathrm{dl}$ and because the sample sizes were smaller. Despite this, the galactose and glucose curves are similar, again suggesting that galactose and glucose are absorbed from the intestine at approximately equal rates. Also, the areas under the galactose and glucose curves in Figure $6 B$ are 78 and $24 \%$ more, respectively, than the areas under the two curves in Figure $6 A$ (Table 2). This 


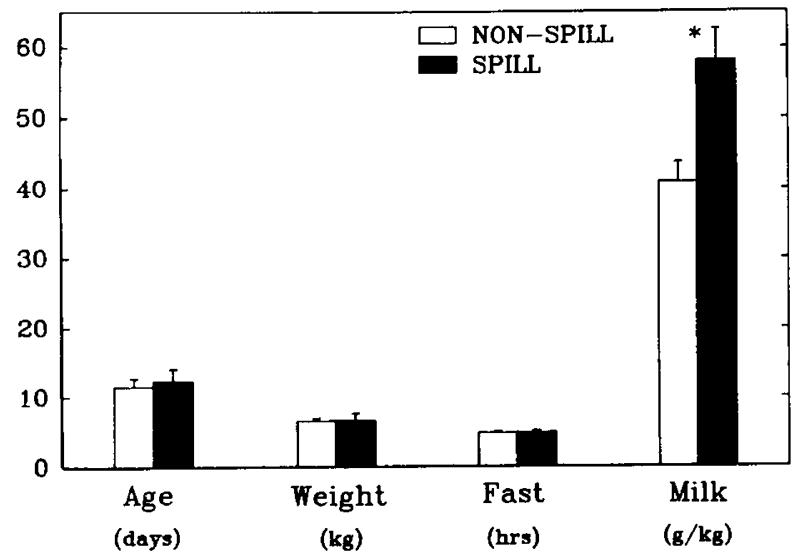

Fig. 5. Comparison of postnatal age (days), weight ( $\mathrm{kg}$ ), fast-time (h), and milk intake $(\mathrm{g} / \mathrm{kg})$ for each lamb on each study day for the nonspill and spill studies (mean and SEM; asterisk indicates spill significantly greater than nonspill; $p<0.05$ ).
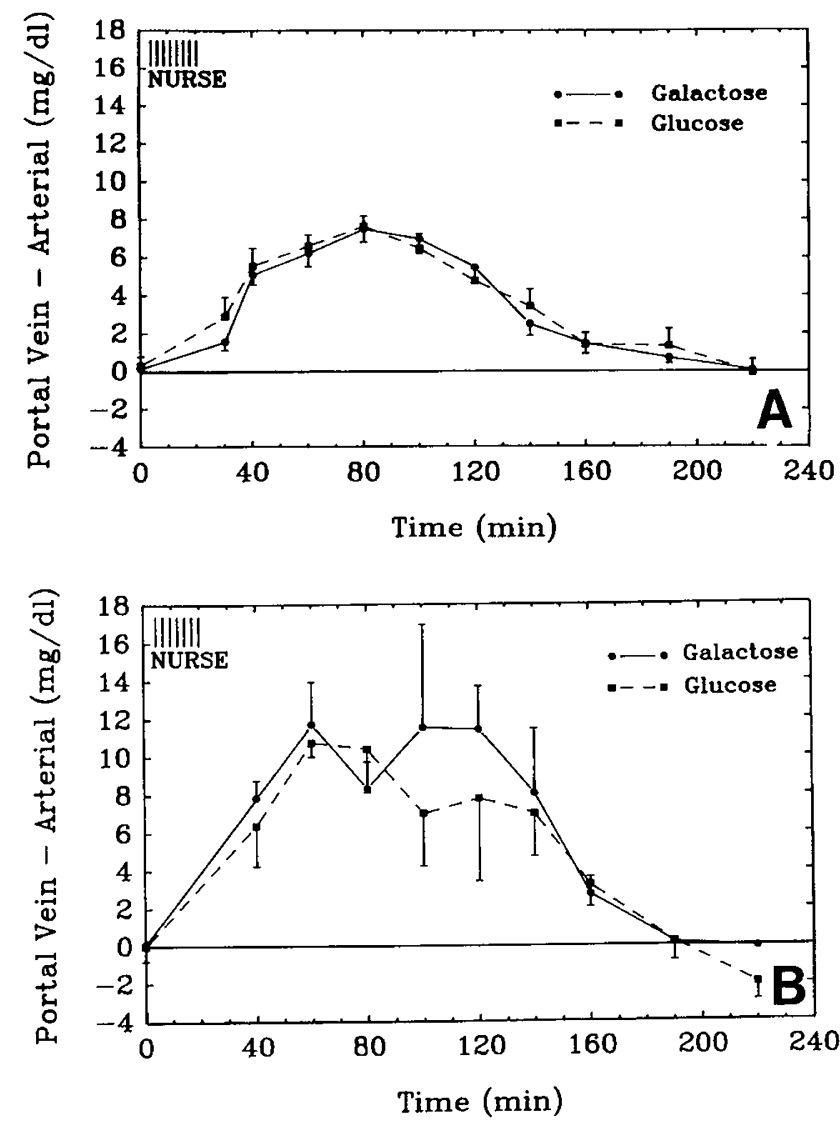

Fig. 6. $A$, portal venous minus arterial concentration for galactose and glucose versus time after nursing for the nonspill studies (mean and SEM). $B$, portal venous minus arterial concentration for galactose and glucose versus time after nursing for the spill studies (mean and SEM).

average increased area under the curves of $51 \%$ is similar to the greater milk intake seen in the spill studies (41\%) (Fig. 5) and suggests that milk intake on a particular study day was a principal determinant of whether a lamb had a nonspill or spill study.

\section{DISCUSSION}

There is an extensive body of literature concerning lactose and galactose metabolism in humans and other mammals $(2,8)$. Most previous in vivo experiments have used either adult subjects or were acute studies. The present lamb study was designed to provide information regarding the unstressed newborn mammal, implanted with chronic, indwelling catheters that permit the study of carbohydrate metabolism after normal nursing.

This study demonstrates that newborn lambs have a significant postprandial increase in the portal venous galactose and glucose concentrations after lactose ingestion (Figs. $2 A$ and $B, 3 A$ and $B$ ). Ulbrich et al. (9), Char and Rudolph (10), and Ferguson et al. (11) reported an increase in peripheral glucose concentration in lambs after lactose ingestion but no measurements of galactose concentration were done nor was the portal venous circulation sampled. Coombe and Smith (12) using preruminant calves, Williams et al. (13) studying adult humans, and Siegel et al. (3) studying human newborns each demonstrated large increases in peripheral glucose concentration and much smaller changes in peripheral galactose concentration after lactose ingestion, similar to the arterial data we report in Figures $2 A$ and $3 A$. Siddons et al. (14) gave lactose to preruminant calves and found quantitatively large increases in peripheral and Glupv with much smaller

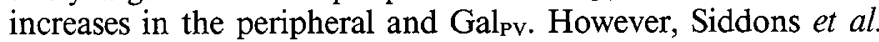
(14) estimated galactose concentration from the changes in blood reducing substances and glucose concentration.

Our findings indicate that after lactose ingestion, galactose and glucose are absorbed from the intestine into the portal venous circulation at approximately equal rates (Fig. $6 A$ and $B$ ). At first glance these data are in apparent contrast to human $(13,15,16)$, calf (12), and rat (17) data in which the presence of glucose in the intestine slowed the absorption of galactose much more than galactose slowed the absorption of glucose. However, three important differences in our study design may explain this discrepancy. First, we obtained blood samples from the portal vein which receives venous drainage from nearly the entire small and large intestine. In four of the above-mentioned studies $(12,15-$ 17 ) only a relatively small portion of the upper intestine was studied; therefore, differential absorptive rates for galactose and glucose in the rest of the intestine would be missed. That such differential absorptive rates exist had been demonstrated in the newborn lamb (18). Second, one study (13) did not sample portal venous blood making any inferences regarding rates of carbohydrate absorption from the intestine difficult. Third, there may be a species-specific difference in the rate of intestinal carbohydrate absorption; although, given the technical and methodological differences in the various studies, this last explanation may be the least likely.

Herein there was no significant increase in $\mathrm{Gal}_{\mathrm{A}}$ when $\mathrm{Gal}_{\mathrm{PV}}$ was $<10 \mathrm{mg} / \mathrm{dl}$. The liver apparently clears the portal venous circulation of galactose after lactose ingestion at normal postprandial portal venous blood flows, but its threshold to do so is exceeded at $\mathrm{Gal}_{\mathrm{pv}}>10-12 \mathrm{mg} / \mathrm{dl}$. In $20 \%$ of the studies this threshold was exceeded. Intrinsic interanimal differences in this threshold are probably not the reason a lamb had a nonspill or spill study because three lambs had both types of studies on separate days. Inasmuch as age, weight, and fast-time were similar between the nonspill and spill studies, the most probable explanation for the difference between the two groups was the variability in milk intake (Fig. 5). This hypothesis is strengthened by the observation that the greater area under the curves in Figure $6 B$ as compared to those in Figure $6 A$ (Table 2) is similar to the greater milk intake in the spill studies as compared to the nonspill studies. It is likely that lambs normally do not exceed this hepatic galactose threshold of $10-12 \mathrm{mg} / \mathrm{dl}$ as often as we observed because their natural feeding pattern is not characterized by fasting followed by a large meal, but rather by frequent, small feedings. The concept of a "threshold" in biological systems may be more apparent than real and are inferred from graphical presentation of data such as Figure 1. Whether such an hepatic galactose threshold is best expressed in terms of substrate concentration or substrate delivery (flux) awaits further studies.

It has been well demonstrated that the fetal and neonatal liver can convert galactose to glycogen leading to net glycogen synthesis faster than they convert glucose to glycogen $(19,20)$. The newborn liver converts galactose to glucose-1-phosphate faster in 
the suckling period than the adult period $(21-25)$. The actual rate-limiting step in the hepatic clearance of galactose is thought to be one of the enzymes of the Leloir pathway $(26,27)$, although there is some evidence to suggest it may be hepatic membrane transport of hexoses that is rate limiting (24). We have shown in lambs that the hepatic capacity to clear galactose from the portal venous circulation in the unstressed, postprandial state is exceeded when the portal vein galactose concentration is more than 10-12 mg/dl. Although not directly comparable, Waldstein et al. (28) have shown the hepatic threshold for galactose clearance in two adult males to be approximately $30 \mathrm{mg} / \mathrm{dl}$, and Berman et al. (29) have demonstrated that the maximal capacity for galactose conversion to glucose in the isolated rat liver is reached at a galactose perfusate concentration of $18 \mathrm{mg} / \mathrm{dl}$.

Studies in lambs (10) and premature infants (30) have shown increases in peripheral lactate concentration after lactose ingestion. Davis et al. (31) have elegantly demonstrated in a canine model that the source of the lactate increase seen after a mixed nutrient meal was mainly the liver and not the intestine. Our data in lambs are consistent with this observation; we found a small but significant increase in the lactate concentration after lactose ingestion which was similar in both the arterial and portal venous circulations (Fig. 4). Thus, lactate is not absorbed from the intestine into the portal venous circulation to any great extent after lactose ingestion in the newborn lamb.

In summary, we have developed techniques for chronic catheterization of the newborn lamb that permit normal nursing to be reestablished with the mother so that carbohydrate metabolism can be studied in the unstressed postprandial state. Further studies using this lamb model are needed to elucidate hepatic galactose and glucose metabolism and their relationship to the synthesis and breakdown of glycogen.

Acknowledgments. The authors recognize the excellent technical assistance of Susan Anderson during the course of this study.

\section{REFERENCES}

1. Battaglia FC, Meschia G 1978 Principle substrates of fetal metabolism. Physiol Rev 58:499-527

2. Williams CA 1986 Metabolism of lactose and galactose in man. Prog Biochem Pharmacol 21:219-247

3. Siegel C, Sparks JW, Battaglia FC 1988 The patterns of serum glucose and galactose concentrations in term newborn infants after milk feeding. Biol Neonate (in press)

4. Hjelm M, deVerdier C 1974 Determination with galactose oxidase. In: Berg meyer HU (ed) Methods of Enzymatic Analysis, 2nd ed, vol 3. Academic Press, New York, pp 1282-1287

5. Freund RJ, Littell RC 1981 SAS for Linear Models, A Guide to the ANOVA and GLM Procedures. SAS Institute Inc., Cary, NC
6. Scheffe H 1959 The Analysis of Variance. John Wiley and Sons, Inc., New York

7. SAS Institute Inc. 1985 SAS User's Guide: Statistics, 5th ed. Cary, NC

8. Kliegman RM, Sparks JW 1985 Perinatal galactose metabolism. J Pediatr 107:831-841

9. Ulbrich M, Nienke U, Hakim NFA 1978 Glucose content of lambs' blood. I Effect of administration of various carbohydrates. Arch Tierernahr 28:673677

10. Char VC, Rudolph AM 1979 Digestion and absorption of carbohydrates by the fetal lamb in utero. Pediatr Res 13:1081-1023

11. Ferguson A, Paul G, Snodgrass DR 1981 Lactose tolerance in lambs with rotavirus diarrhoea. Gut 22:114-119

12. Coombe NB, Smith RH 1973 Absorption of glucose and galactose and digestion and absorption of lactose by the preruminant calf. $\mathrm{Br} J$ Nutr $30: 331-344$

13. Williams CA, Phillips T, MacDonald I 1983 The influence of glucose on serum galactose levels in man. Metabolism 32:250-256

14. Siddons RC, Smith RH, Henschel MJ, Hill WB, Porter JWG 1969 Carbohydrate utilization in the pre-ruminant calf. Br J Nutr 23:333-341

15. Holdsworth CD, Dawson AM 1964 The absorption of monosaccharides in man. Clin Sci 27:371-379

16. Gray GM, Santiago NA 1966 Disaccharide absorption in normal and diseased human intestine. Gastroenterology 51:489-498

17. Fisher RB, Parsons DS 1953 Galactose absorption from the surviving small intestine of the rat. J Physiol 119:224-232

18. Scharrer E, Liebich HG, Raab W, Promberger N 1979 Influence of age and rumen development on intestinal absorption of galactose and glucose in lambs. A functional and morphologic study. Zentralbl Veterinarmed [A] 26:95-105

19. Sparks JW, Lynch A, Chez RA, Glinsmann WH 1976 Glycogen regulation in isolated perfused near term monkey liver. Pediatr Res 10:51-56

20. Kliegman RM, Miettinen EL, Kalhan SC, Adam PAJ 1981 The effect of enteric galactose on neonatal canine carbohydrate metabolism. Metabolism 30:1109-1118

21. Segal S, Roth H, Bertoli D 1963 Galactose metabolism by rat liver tissue: influence of age. Science 142:1311-1313

22. Ballard FJ, Oliver IT 1964 Ketohexokinase, isoenzymes of glucokinase and glycogen synthesis from hexoses in neonatal rat liver. Biochem $\mathbf{J}$ 90:261267

23. Ballard FJ, Oliver IT 1965 Carbohydrate metabolism in liver from foetal and neonatal sheep. Biochem J 95:191-199

24. Berman WF, Rogers SR, Bautista JO, Segal S 1978 Galactose and glucose metabolism in the isolated perfused suckling and adult rat liver. Metabolism 27:1721-1731

25. Rogers S, Guerra M, Segal S 1983 Galactose metabolism in suckling and adult isolated rat hepatocytes. Pediatr Res 17:609-616

26. Goresky CA, Bach GG, Nadeau BE 1973 On the uptake of materials by the intact liver. $\mathrm{J}$ Clin Invest 52:991-1009

27. Keiding S, Johansen S, Winkler K, Tygstrup N 1976 Michaelis-Menton kinetics of galactose elimination by the isolated perfused pig liver. Am J Physiol 230:1302-1313

28. Waldstein SS, Greenburg LA, Biggs AD, Corn L 1960 Demonstration of hepatic maximum removal capacity $\left(\mathrm{L}_{\mathrm{m}}\right)$ for galactose in humans. J Lab Clin Med 55:462-475

29. Berman W, Rogers S, Bautista J, Segal S 1979 Galactose metabolism in isolated suckling-rat liver. Am J Physiol 236:E633-E637

30. Lifshitz F, Diaz-Bensussen S, Martinez-Garza V, Abdo-Bassols F, del Castillo ED 1971 Influence of disaccharides on the development of systemic acidosis in the premature infant. Pediatr Res 5:213-225

31. Davis MA, Williams PE, Cherrington AD 1984 Effect of a mixed meal on hepatic lactate and gluconeogenic precursor metabolism in dogs. Am J Physiol 247:E362-E369 